\title{
Automating the digital media supply chain-Interview with Bill Sheeran of ClearStory Systems, Inc.
}

\section{Bill Sheeran}

spearheads ClearStory's product management and product marketing organizations. His current responsibilities include defining product strategy for the company, directing the technical elements of ClearStory's award winning solutions, managing technology partnerships and developing the channel. Bill has a decade of experience working in emerging technologies, supporting technical sales, marketing and business development organizations for several Enterprise Content Management and Digital Rights Management firms. Bill also has eight years' progressive project management and software development experience, managing corporate IT development teams that designed and deployed client/server applications and systems for a private contract services firm. Bill holds a Bachelors degree in MIS and Finance from University of Massachusetts.

Keywords: business process management, workflow, content management, multi-tenant architecture, ClearStory, enterprise media server

Abstract ClearStory, having over the last year or so planned and executed the embedding of a business process management engine into their product, has researched developments in the field of workflow automation for marketers and marketing agencies. The growth rates of hosted solutions seem to indicate that in the next 24-36 months, SaaS will take a majority share of the total DAM implementations. Bill Sheeran of ClearStory spoke with us recently on the thinking behind the new direction the DAM industry is taking with respect to collaborative platforms and DAM. Journal of Digital Asset Management (2008) 4, 269-276. doi:10.1057/dam.2008.34

MM: If you would, Bill, give us some background, in terms of your professional career. BS: My name is Bill Sheeran. I'm currently the director of product management and marketing at ClearStory Systems, Inc. Over the last ten years, I've been working in and around content management technologies.

Early on, I started out in the WCM and ECM space and later worked within digital rights management and document encryption. Since then I've been with ClearStory — going on three years.

ClearStory is actually the rebirth of a late '80s company called INSCI Corp. INSCI was in the business of document-based content management. Software used to manage business statement presentment and archive, hightransactional types of systems - both scanned and digital original.

MM: Those would be like checks and statements like a bank or financial services firm might generate?

ClearStory Systems, Inc., One Research Drive,

Westborough, MA 01581, USA

Tel: +15088704000
BS: Yes. Exactly right.

As that market plateaued in the late ' 90 s, strategically we were looking into the next wave of digital content technologies. In 2002, we acquired Webware, which is well known as the pioneer in web-based digital asset management. At that point we reemerged as ClearStory Systems.

Since that acquisition, we've made heavy investments into rearchitecting the Webware solution on contemporary standards - resulting in a pure Java or J2EE enterprise media server application upon which all of our applications are currently built and distributed.

MM: Great.

As I understand it, Bill, ClearStory offers a pure software-as-a-service (SaaS) capability? BS: ClearStory is, at the very heart of it, a software company. When we acquired Webware they were already hosting about half of their clients' solutions. This naturally imposed SaaS requirements as part of rearchitecting the enterprise media service solution that was pioneered by Webware. So we emerged with key capabilities to support SaaS quite effectively.

As we progressed through DAM's second- to third-generation evolution, moving from workgroup or departmental solutions toward 
enterprise solutions, the system was built such that it leverages more enterprise-class technologies. Not only integrating with a lot of pre-existing technologies that might exist in an IT infrastructure for any enterprise, we also made the solution highly scalable and very performance-centric. It is a multi-tiered solution with a clear separation between the enterprise media server, its backend storage mechanisms and its front-end presentation applications like ActiveMedia $^{\circledR}$, the web-based end-user DAM application.

I guess the key information that we gleaned in that second- to third-generation evolution was the need for a multi-tenant architecture. The idea was that in large enterprise organizations (and in SaaS environments) you have multiple teams (or tenants) in the system. In any given product-based company, for example, you'd have a product management team, a product marketing team and maybe a corporate marketing team. These teams may work together or apart, entirely or on occasion.

With a multi-tenant environment, many different groups — workgroups, organizations, domains, companies, lines of business - could all participate in a single stack of hardware systems, with a security model that allows either complete segregation of those constituents and different users or a blended integration of some higher-level roles with access to multiple domains. Lower-level roles would just have access to their unique sub-domain so they could work as a workgroup within a larger hierarchy.

So almost immediately on our release of the rearchitected solution - what we refer to as a third-generation DAM application - it lent itself very well to a SaaS model.

Now, leveraging that same security model and multi-tenant environment, we're able to provide a very cost-effective entry point for companies small and large: for small marketing workgroups in small companies, but also multiple work teams in very large companies. It adapts quite well, to both a hosted and an installed model, which is how we offer it today.

MM: Bill, let's use this as an opportunity to shift into the primary focus of our interview today - which is really dealing with DAM and agencies, and creative services groups that may or may not be part of a larger Marcom operation or marketing operation.
Could you outline for us some of the key developed trends and developments in DAM for creative services groups or advertising agencies? BS: Sure.

A couple of key requirements that creative services groups, as well as agencies, impose on DAM systems, particularly at the enterprise class, are: one, creative teams are not focused on the management of the content — the asset - or the repository. As they should, they focus on the creative elements; they focus on the ability to create new items or manipulate and update existing items. That is their role in the organization.

That imposes upon the DAM solution the responsibility of giving creative design teams an interface that allows them to very closely adapt what they work with on a day-to-day basis but then present their finished content into the DAM repository - and then have other teams or other marketers in the organizations maintain that environment and maintain the information that describes it - such as metadata and taxonomies. But also to maintain the ability for that content to reach its endpoints through the distribution channel, different sales organizations or whatever the case may be.

You see, they focus on the creative element - but then provide a handoff to the rest of the organization - to take care of the management and fulfillment that occurs in and around that media once it has been produced.

MM: As we look or examine the creative workgroup, I'm going to outline four or five key stages or areas that often require specific capabilities that may or may not come from a DAM. I'd like you to speak to each of those requirements or capabilities. Let me just enumerate them quickly and then have you address them individually.

Generally, most agencies react to the needs of the client. So therefore, often the over-thehorizon radar capability that really helps agencies is scheduling - times and dates remaining fluid. It's more of a collaborative, iterative notification of upcoming work, so that we can resource it appropriately. Also there's project definition and project management. That's really about setting up specific workgroups and/or teams with appropriate work and specifically with deadlines, timelines and budgets. 
Then the next piece is project tracking or workflow status reporting.

The next piece of that is the review-andapproval piece. There are two levels of review and approval. Review and approval at the metadata level - comments about the asset, but not any direct commenting to the asset. And then there's actual commenting to the asset vis-à-vis a remote proofing system.

Then once you have that, there's the publishing of the data to some sort of selfservice portal, which is the first half of a distribution system. Then the second half of the distribution is how we can automate the zipping up or packaging of any number of assets into a more compact, easily transported package. That also might include a specialized digital logistics or digital transport capability. Then finally, a social media piece - which is more of a discussion around the use of and ongoing applications of items in the repository.

As a kind of spectrum, could you speak to the scheduling and/or project management piece?

BS: Effectively, you are describing the recent evolution of our product line. First and foremost, you're speaking to creative teams or marketing teams managing that marketing calendar as it relates to digital media.

Then there is resource management, where projects are being created and processes are being followed and resources are being expended as well as tracked. That leads me to the next one, which I believe speaks to utilization of those same resources - both internally and externally through third parties or through outsourcing.

Next is the review-and-approval process: the routing of those newly produced or newly updated assets throughout the organization in an objective to reach some level of authorization that the state of that asset can now take on a "published" status.

Finally, you are speaking to the distribution of that media and content to a much wider audience, directly to that end consumer in either a $\mathrm{B} 2 \mathrm{~B}$ or $\mathrm{B} 2 \mathrm{C}$ model.

That's where our current release is heavily focused: workflow automation. As I said earlier, ClearStory rearchitected our solution to take it from second-generation to third. We are now at the inflection of third- to fourth-generation, where we've effectively consolidated a lot of different marketing requirements. As you and I have spoken about previously, you take the genres of marketing technology - you list out your acronyms - MOM, MRM, MAM Operations Management, Resource

Management, Asset Management. We've tried to incorporate everything that those genres or groups of technology produce into some wide distribution model over the corporate web to different media devices, to consumers, to retail outlets.

That's really where we're focused. Over the last 12-18 months, we've been planning and executing the embedding of a business process management (BPM) engine into our product, then leveraging all of that utility.

A BPM engine - to keep it at a high level — is basically going to provide the scheduling and the ability to create a process, and then instantiate that process in the context of some object. In this case, the object is an asset, or group of assets.

We are now able to give a DAM user with the appropriate privileges the right to create a project, and have that project follow a consistent process. As we were evaluating the DAM space specifically, as well as the process management space in general, we did find that on the marketing side or on the marketing resource management side, it tended to focus too heavily on those strict routing, review and approval capabilities.

Everything out there focused around the authorization of an asset to be distributed.

Of course, we included all of that utility in our product. But we felt that it left out two key aspects. One involves supporting the creative process without disrupting the way that those creatives developed. On the flip side, we have extended the process to include all of the downstream distribution tasks that tend to occur immediately following that approval step. We wanted to broaden the swim lanes around workflow, in general.

MM: That brings up a great point, Bill. Specifically, as we look at more sophisticated BPM or BPM tools - as they apply to the content supply chain or media supply chain. Specifically, as you're beginning to speak to it, the initial part of the overall lifecycle begins 
with ideation. Ideation really doesn't produce any assets, per se. It produces a lot of metadata. It produces things like a marketing brief or a creative brief. It creates concepts and conversations that tend to reflect a very iterative, circular process that really highlights communication, interaction and collaboration among teams.

That ultimately then starts to take shape in terms of a project. But it doesn't really become a project until it gets budgeted, resourced, authorized and so on. At that point, the nature of the rules changes to much more of a linear, procedural process.

Could you speak to how your BPM engine supports that initial phase of ideation - and specifically a lot of that nonlinear iterative, circular communication, interaction and collaboration?

BS: Sure. I'd be the first to admit that in our workflow experience, or process management, we are crawling - we are not yet running.

The end state is really in flux at this point, in that there are some great tools out there that have emerged which speak specifically to that ideation model - collaboration rooms and collaboration technologies - a whiteboard space for online meetings and brainstorming. I have, however, not encountered one that incorporates even the most basic features of DAM or support for media repositories beyond online folders.

$\mathbf{M M}$ : Are there any in particular that come to mind as examples for more of a Web 2.0 version of those capabilities?

BS: Certainly, my favorite that I use on a day-to-day basis is Adobe Connect. It is a Flash-based Web Meeting environment. It extends my desktop to anybody I am communicating with over the web. With respect to your comment that these digital media projects begin with that ideation process I think some of those tools are expressed very well.

Our workflow software release is essentially focused in and around the constructs required to create and execute automated processes. We are getting all of the appropriate functional pieces in place. We've already begun work to express those in Web 2.0 applications for more of a collaborative environment as we move forward. In the near-term roadmap for ClearStory, a lot of those tools and a lot of those applications, I think, are going to become mainstream tools that clients will want integrated with DAM systems.

Whether they happen as a result of synergies between technology partnerships or whether they become homegrown is really dependent on how quickly the market picks up on it - how quickly the demand grows for this type of endto-end solution involving everything from womb-to-tomb as far as the digital asset is concerned.

MM: One of the things we've seen in the ideation process - along the lines of Adobe Connect - has been another capability, referred to as "instant workspaces." They not only maintain a real-time connection, but they also then become asynchronous or stored offline. So you can have people at various times of the day plugged into the workspace, doing their reviewand-approval. But it still maintains a persistent state online, so that when you disconnect, the workspace doesn't disappear.

In particular, I'm speaking about an interview that we did in the Journal, Volume 3, Issue 6, with Henry Hon and Todd Lane of Vyew.

Another one we've seen that's emerged as an interesting little smart client is from a company called Apeer. Have you heard of other, similar applications on your radar, in terms of that kind of front-end workspace collaboration?

BS: Yes. By the way, I'm a big subscriber to the Journal of $D A M$ - that's where I first heard of Vyew — in that issue. I also like what Octopz is doing with their online collaboration tools.

I think collaborative workspaces are important, certainly with respect to marketing agencies. Agencies that work for other companies in branding initiatives, and also marketing organizations within larger corporations, need to find ways to move the project along efficiently. I'm just not sure that there's enough demand specifically in the marketplace for these types of technologies to supercede a lot of other issues that marketers have with respect to the production and distribution of brand assets.

We frequently hear from customers about the lack of focus out there on what we call postproduction issues. The asset is created and readied and then put somewhere. But it's put 
somewhere in such a location that it's not selfservice accessible. It's not appropriately protected with regard to IP and with respect to different roles in the organization, as well as different relationships with third-party agencies.

I think, certainly as a technologist, I understand and respect that these are great applications. But as they relate to the day-to-day issues that face marketers, I think at this point they're not really focused on the publishing and distribution aspect. Instituting some production standards or some repeatable processes around that digital media supply chain offers a tremendous value to marketers. I expect that once marketers have efficient production methods, they will want better tools and support for online collaboration. This was the case in content management and portals.

MM: Perhaps we can use this as an opportunity to shift a little deeper into discussing some use cases, with the idea of focusing on agencies or creative services groups.

What are some of the best practices that you see evolving in those areas?

BS: I think that with respect to marketing organizations or agencies that work on behalf of marketing organizations, they're ultimately faced with doing more with less. It's clear to me that there are many different types of new media that exist today, very few of which even existed in the mainstream three or four years ago. Flash media for example.

The ability for marketers to jump on the bandwagon - even in regard to social networking, being able to leverage application environments that would allow them to promote their brands and reach new consumer markets.

The marketing organization needs to focus on their ability to resolve some longstanding issues within their departments, in regard to their production process and the ability to become a very efficient organization, as well as to become an adaptable organization, to focus on new technologies - and to be ready for it when it comes.

I see a tremendous acceleration in the shifting of technology to technology on a day-to-day basis. Yet you look at statistics across product manufacturing companies but also in new media companies. Marketing budgets are not growing at a rate to keep pace with the growing costs of acquiring new technologies.

Particularly for ClearStory, but I suspect that it's in the DAM marketplace in general, a lot of these marketers are looking to leapfrog over a lot of technology that may be outdated or misused. There is a strong desire to get involved in the most current technology out there - but only those that focus on delivering immediate cost efficiencies to their organizations. It tends to be about the bottom line and measurable results.

MM: Something you just mentioned, in terms of a change in how marketers operate today it has to do with what I call the Google effect. Google has fundamentally changed the engagement strategy for a lot of firms.

In the past, most firms organized their marketing around campaigns. Campaigns constitute a procedural system, where you've got a big customer insight and you validate the customer insight with primary and secondary research. You then develop a strategy - kind of an overall branding and go-to-market strategy. "What are all the resources that we need to align and direct, so as to achieve competitive advantage?"

Then once you've got a strategy to execute, that then leads to either a product launch platform or a creative brief. They go off and they do their stuff - which we've already characterized as ideation, scheduling, project management, project tracking, review-andapproval and distribution.

Then comes the launch date - boom. We pull the trigger and we paint the town red with our brand-marketing message. Ideally, what happens is that the outdoor advertising corresponds with the in-store point-of-purchase merchandising. That corresponds with the call center having the appropriate scripts and Webcast theaters doing their thing. Direct mail is hitting the homes or businesses. Print and broadcast are lighting up their particular theaters.

You get synergy across all of these media formats. But the problem with that particular model is that as each day goes by, there's a diminishing return. Customers are no longer passively waiting for someone to market to them. They're out Googling away. They're searching out and sorting out things, and they're 
getting information on your product before your launch date.

So in many respects, the customer now is Googling around and coming to the front door of these brand marketers - prepared or not for these visitors. These consumers now become more self-directed and they engage in the entire spectrum of a brand interaction.

So marketing has undergone a structural transformation away from this linear, procedural marketing communications format - to much more of a 360-degree engagement strategy that entails having brand interactions throughout an entire lifecycle.

When you start talking about how you start to plan for customer engagements, fundamentally it means that you have to have your marketing communication assets in far more fluid formats. So then you can instantly reshape and record them and reuse them.

Does that summarize or is that a good setup for how agencies are beginning to reconstitute their business model and using technology to facilitate that?

BS: I agree. I think it just effectively boils down to the fact that marketers today have to manage all of those channels at once. Without looking at automation systems to support them in doing that I don't know how they could cope. Without a central repository they can't maintain consistency across all of these channels.

I think what's of most concern to marketers is that they haven't been through this before. You look at how technology has impacted corporate departments over the last 20 years. Marketers are the ones who effectually are the last to get to come to the table.

You have the finance organization gone digital in the early ' 90 s; the sales organization on CRM - even as early SaaS adopters - and product teams doing automation, production assembly, supply chain management and other things of that nature.

Now I think, at least in and around the DAM space, we're working with people who have not been accustomed to this shift in technology systems. I think that's why they tend to seek partnerships with vendors like us - rather than just being a consumer of our software. They are very much attracted to SaaS models. They represent a low-risk, high-value, no hassle alternative to lengthy IT projects.
In truth, they are really looking for us to help shape their solutions right out of the gate and then have a consistent relationship with several technology companies at once. In fact, most of our customers - for example Grace \& Wild, which is a leading post-production video house that uses our solution to provide a value-added service to their customers, they took our technology and now effectively manage the accessibility of their own customers' content through our SaaS offerings.

It is truly this digital media supply chain that the marketers are trying to get a handle on. I think, though, to get back to your Google analogy - at least for us software vendors, there's a love-hate relationship with Google. It presents itself as a utility that allows us to market at a very low cost. Without Google, who knows? We may be running more expensive promotional projects to get that same kind of traction.

But at the same time, Google, the applications company, is offering very compelling solutions - effectively for free - to basically drive customer loyalty in and around the Google environment. And it's tough to compete with a free solution.

MM: Can you speak to what an advertising agency client is doing with ClearStory technology?

BS: Most agencies that we are working with actually have multiple DAM solutions in place to serve a variety of needs. I think if you look closely at the agencies' market, you would see that no matter how big or small those companies are, they tend to have small working groups that get accustomed to their own solutions for their own accounts.

It again goes back to speak to the digital media supply chain. The idea that companies agencies - are not just providing value-added DAM services, but are now providing DAM services mandated by their clients - to make all of the content they produce for those clients available 24/7.

I see a much bigger shift toward the global media production market - just in the last 18 or 24 months. The work teams around marketing - not just in the ideation process, but also in the post-production process. They have this 360-degree engagement cycle. We have all of these different outlets for digital media. Each one may have unique purposes. 
You may need to tweak the content just before its placement and its appropriate positioning. Whether that's on a website or on an electronic billboard, the messaging is the same. The content - certainly from a marketer's perspective, needs to be consistent. But the format may need to be altered in order to make it more compatible with its placement, on the web or over the highway.

What I see is a much greater focus on the distribution of content, rather than on where vendors previously focused. Perhaps we have solved the creation aspect as it relates to digital asset management.

MM: As we begin to wrap up here, what sort of future proofs do you see?

BS: From ClearStory's perspective, we have focused a lot of attention on our architecture and our core capabilities. Our latest release focused on workflow utilities that provide scheduling and task automation by embedding a BPM engine. It took us quite a while to select the BPM engine that we put in. Once we did, everything flowed in nicely, and I think we made a great decision.

MM: If I may ask, can you say which one you put in?

BS: It's the JBoss - jBPM. As far as we know, it captures a large portion of the marketplace.

Because our Enterprise Media Server was already based on JBoss, the application server, it was a great fit for the platform.

MM: So JBoss was traditionally a middleware and open-sourced middleware capability, but then once you pull it into a SaaS environment, it becomes a BPM platform. Is that a fair characterization?

BS: Absolutely. That is a perfect characterization. Really, our objective was to take those capabilities, the BPM services and provide a simple-to-use interface to support the assembly and creation of media processes.

Our objective was in keeping the user out of the technical baseline process management piece. With our product, there's no need to assemble XML documents or come up with fancy flowcharts that all point back to individual services or API methods.

We've extended the nontechnical interface of Active Media in the context of creating a project - associating tasks in a serial fashion. This enables the user to easily set up repetitive procedures for producing and distributing digital media.

People tend to relate, I think, to workflow process as a step-by-step approach. Some steps go off and take different routes to completion. But ultimately, people work serially — even though they may be in a multitasking environment. That was our approach, and we took a lot of pains to abstract the technicality of a BPM engine, and make it more comfortable and simplistic to serve a broad base of users.

We do focus greatly on our architecture, to your point, to try to be future-proof. We changed our architecture in the embedding of the BPM engine and we expect the new capabilities to allow us to easily develop new automated features for managing the digital media supply chain. With workflow utility at the core, we can develop new features that will be easy to automate, such as delivering reports and analytics back to business owners such that they can derive measurable and actionable results to improve how and what they produce with the system.

We focus very much on the core of our product. We focus a lot on the engine. We think that the benefits we get in the long term from that focus will allow us to acquire a larger portion of the DAM market - with respect to SaaS. A solid core allows us the flexibility to develop vertical SaaS solutions to meet the disparate requirements in several key markets, like CPG and M\&E. Certainly the growth rates of hosted solutions seem to indicate that in the next 24-36 months SaaS will take a majority share of the total DAM implementations. We need to focus and make sure we get the engine right. Then how we express the utility of that engine to the end users really becomes more of a decision between us and the market or us and the particular customer.

MM: What sorts of developments have you seen of what we call "master class consultants," shepherding the purchase and deployment of some of these more advanced systems. BS: A couple of providers come to mind. We have long-standing relationships with integrators like SDG, Cognizant, and Infosys. They understand the power and importance of the underlying architecture behind the scenes. 
With a lot of these engagements, the business requirement changes over time. That's a natural occurrence. As that business changes, you don't want to change the entire vehicle - to continue with my engine comparison. But certainly, you do want to change the chassis or add components to it, and make it more integrated with a lot of other technologies that certainly do not exist today - or may not be in scope. These providers are creating complete eco-systems, if you will, around core DAM systems.
I think the ability of our partners to take our service-oriented architecture and plug these services into a lot of different other technologies is key to successful deployments. But for the most part, they are able to assemble more of a best-in-class solution that serves their customers well.

MM: Great. We'll conclude on that.

BS: Thank you Michael. We appreciate the opportunity to share our story and vision for digital asset management. 